\title{
Cloud Computing Governance Lifecycle
}

\author{
Soňa Karkošková ${ }^{\star}$ George Feuerlicht ${ }^{*}$
}

\begin{abstract}
Externally provisioned cloud services enable flexible and on-demand sourcing of IT resources. Cloud computing introduces new challenges such as need of business process redefinition, establishment of specialized governance and management, organizational structures and relationships with external providers and managing new types of risk arising from dependency on external providers. There is a general consensus that cloud computing in addition to challenges brings many benefits but it is unclear how to achieve them. Cloud computing governance helps to create business value through obtain benefits from use of cloud computing services while optimizing investment and risk. Challenge, which organizations are facing in relation to governing of cloud services, is how to design and implement cloud computing governance to gain expected benefits. This paper aims to provide guidance on implementation activities of proposed Cloud computing governance lifecycle from cloud consumer perspective. Proposed model is based on SOA Governance Framework and consists of lifecycle for implementation and continuous improvement of cloud computing governance model.
\end{abstract}

Keywords: Cloud computing governance, SOA governance, SOA Governance Vitality Method, Open Group, Cloud computing governance lifecycle.

\section{Introduction}

Over the last decade, a number of governance frameworks for information technology (IT) have been developed (Jäntti \& Hotti, 2015). Commonly used IT governance frameworks are COBIT, ITIL, ISO 38500 and governance for service oriented architecture (SOA). Most of IT governance frameworks does not have any available guideline for their implementation in enterprise (Joukhadar \& Rabhi, 2015). Due to excessive complexity and scope of IT governance frameworks, many organization do not fully implemented these frameworks or do not implemented these frameworks at all (Pour, 2012). SOA Governance Framework helps organizations to define and deploy their own enterprise governance of SOA (The Open Group, 2009). SOA Governance Framework contains SOA Governance Vitality Method which is a cycle consisting of phases Plan, Define, Implement and Monitor (The Open Group, 2009). SOA Governance Vitality Method defines a complete method for establishment, monitoring and improvement of SOA governance model in particular organization (Königsberger, Silcher, \& Mitschang, 2014).

\footnotetext{
* Department of Information Technologies, Faculty of Informatics and Statistics, University of Economics, Prague,

W. Churchill Sq. 4, 13067 Prague 3, Czech Republic

$\triangle$ xkars05@vse.cz,jiri.feuerlicht@vse.cz

† Unicorn College, V Kapslovně 2767/2, 13000 Prague 3, Czech Republic
} 
Cloud computing is a model of delivering shared and configurable computing resources (eg. applications, storage, servers, etc.) as a service which can be rapidly provisioned over network on-demand without service provider interaction (Gai \& Li, 2012). Cloud computing has become highly demanded due to its benefits (eg. IT cost reduction) which are well known and widely recognized (Bayramusta \& Nasir, 2016). Along with utilizing cloud services, a number of areas which require a careful consideration had arisen. These are mostly concerning data issues, legal requirements, auditing issues and long-term viability of cloud service provider (Bailey \& Becker, 2014). Governance in cloud environment helps to realize benefits resulting from the use of cloud computing services while minimizing risk, optimizing investments and ensuring compliance with legislative and regulatory requirements (ISACA, 2014). It ensures oversight of qualitative parameters of cloud services such as performance or security which are needed to carefully monitor to ensure the creation of business value (Linthicum, 2009).

Cloud computing and service oriented architecture (SOA) are related approaches which focus on services and thereby both cloud and SOA share some basic principles (Hui-min et al., 2013; Zhao \& Zhou, 2014). SOA and cloud computing may coexist, complement and support each other (Zhao \& Zhou, 2014). SOA can help create conditions for successful adoption and governance of cloud computing services. Common principles of both SOA and cloud computing represent a good predisposition for a unified governance system (Mircea, 2010).

This paper proposes Cloud computing governance lifecycle which is based on SOA Governance Framework. SOA Governance Framework enables organizations to define and deploy their own SOA Governance model adapted for specific business environment. This paper shows what is needed in order to achieve effective implementation of cloud computing governance. This paper adapts methodological components of SOA Governance Framework and extends them for governing cloud computing services. These methodological components, which are after their adaptation suitable for cloud computing governance, are part of proposed Cloud computing governance lifecycle and serve as a base of cloud computing governance. Their adaptation is based on scientific research and on practice in a large IT organization. The original contributions of this paper are:

- Adaptation and redefinition of SOA Governance Vitality Method (SGVM) for cloud computing environment taking into account structure of SGVM

- Definition of maturity level of cloud computing governance based on IT governance maturity level

- Adaptation and redefinition of SOA Governance Reference Model guiding principles for cloud computing environment

- Adaptation and redefinition of SOA Governance Reference Model governed processes for cloud computing environment

- Redefinition of SOA Governance Reference Model governing processes for cloud computing environment

- Adaptation and redefinition of SOA Governance Reference Model structure, roles and responsibilities for cloud computing environment

- Redefinition of SOA Governance Reference Model artifacts for cloud computing environment

This paper is structured in five sections. Related literature is reviewed in the next section (section 2). The exploration of SOA governance and cloud computing governance in the literature shows their mutual relationship and describes proposals of guideline for implementation of SOA governance. Research of prior literature reveals the scarcity of cloud 
computing governance and its implementation concepts. In section 3 proposed Cloud computing governance lifecycle based on SOA Governance Framework is introduced. Section 4 describes verification of Cloud computing governance lifecycle. The last section (Section 5) gives conclusions and directions for the further work.

\section{Literature review}

Service-oriented architecture (SOA) is an architectural style that supports service orientation which can be used to build enterprise IT (The Open Group, 2013). SOA establishes an architectural model where services represent logical solution, which helps to increase efficiency, agility and productivity of organization (Erl, 2007). Implementation of SOA is a demanding activity, given resources and time, which may end in failure to achieve benefits of SOA (Joukhadar \& Rabhi, 2015). SOA governance provides a framework for achieving benefits and business value from successful implementation of SOA (Dehghani \& Emadi, 2015). SOA governance is defined as a combination of organizational structures, people, technologies, policies and processes, which ensures that SOA works properly and in accordance with business requirements and needs of business process (Biske, 2008).

Due to cloud computing represents a set of services, SOA governance principles and processes can be after their adaptation to aspects of cloud computing used to govern cloud computing services (Laird, 2011). Cloud computing governance can be seen as an extension of SOA governance (Fortis \& Munteanu, 2014). Cloud computing governance, as any type of governance in enterprise, focuses on creation, communication an enforcement of policies for the area of using cloud computing services (Munteanu, Fortiş, \& Copie, 2013). Cloud computing governance facilitates and makes more transparent communication between provider and consumer (ISACA, 2014), helps to minimize risk related to use of cloud services (Ritchey, 2009) and define organizational roles and responsibilities as well as processes to govern cloud services and controls to assure that processes operate in compliance with governance policies and legal and regulatory requirements (Saidah \& Abdelbaki, 2014). There is no exact definition of cloud computing governance and no one of widely accepted IT governance frameworks reflect the characteristics of cloud computing services and there is no primarily intended governance framework for governing services in cloud computing environment (Feuerlicht, Schneider, \& Tranter, 2012).

There exist several frameworks for SOA governance (IBM, 2009; Joukhadar \& Rabhi, 2013; Oracle, 2013; The Open Group, 2009). In recent years, there have been proposed many SOA governance frameworks and models (Joukhadar \& Rabhi, 2013; Niemann et al., 2008) and some large organization defined SOA governance as a complement to their commercial products. However, many SOA governance frameworks do not have a guideline for their implementation and there is lack of available empirical studies on successful adoption of SOA governance (Joukhadar \& Rabhi, 2015). Another problem is lack of available empirical studies on successful adoption of SOA governance (Joukhadar \& Rabhi, 2015).

SOA Governance Framework published by the Open Group includes a guideline for implementation of SOA governance model which organizations can customize according to their specific conditions (The Open Group, 2009). SOA Governance Framework defines Reference Model and Vitality Method which is process consisting of plan, define, implement and monitor activities with the aim to establish and improve Reference Model of SOA governance in particular organization (The Open Group, 2009). SOA governance is consisted of elements such as processes, organizational structure or roles and responsibilities which are covered in SOA governance lifecycle (Susanti \& Sembiring, 2011). Hojaji and Shirazi (2010) 
presents SOA governance lifecycle as a part of proposed a new framework for SOA governance named AUT SOA governance framework (Hojaji \& Shirazi, 2010). SOA governance lifecycle is based on governance lifecycle of the SOA governance frameworks introduced by IBM and the Open Group (Hojaji \& Shirazi, 2010). SOA Governance Lifecycle is as Vitality Method a four stage process viewed as a continuous improvement loop. SOA Governance Lifecycle consists of phases Plan, Define, Implement and Measure which enable to establish, maintain and improve SOA governance framework (Hojaji \& Shirazi, 2010). The entire implementation process of a new framework for SOA governance is then described by using current state analysis of organization's governance, governance maturity assessment, future state of SOA governance analysis, transition from current to future state and evaluation and assessment (Hojaji \& Shirazi, 2010).

There is no generally accepted framework for cloud computing governance (Feuerlicht, Schneider, \& Tranter, 2012) and authors who deal with cloud computing governance focus mainly on aspects of cloud computing governance or on proposal of cloud computing governance framework, but they do not give any instruction for cloud computing governance implementation (Bailey \& Becker, 2014; Saidah \& Abdelbaki, 2014).

\section{Cloud computing governance lifecycle}

SOA governance simplifies definition and implementation of effective cloud computing governance. There is no unified definition of cloud computing governance (Saidah \& Abdelbaki, 2014). Cloud computing governance is supposed as specialized governance system for governing IT services in cloud computing environment (Brandis, Dzombeta, \& Haufe, 2013) where cloud service provider is external third party company which deliver its services to cloud service consumer. This paper assumes that cloud computing governance is specialization of SOA governance and extends SOA governance policies, processes, roles and responsibilities and other component on specific characteristics of cloud computing from the cloud consumer perspective. Figure 1 shows cloud computing governance and its relationship to SOA governance.

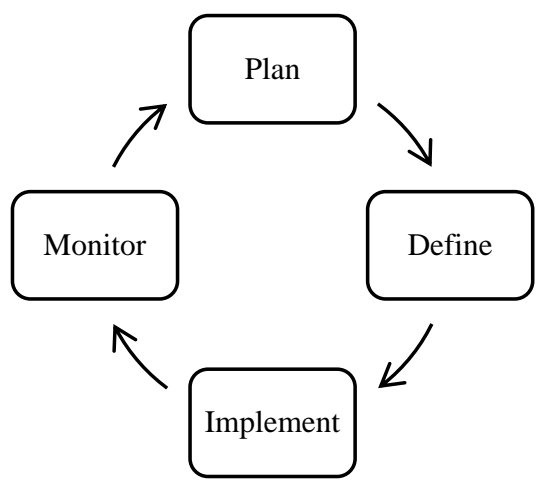

Fig. 1. SOA Governance Vitality Method. Source: authors, based on (The Open Group, 2009).

Due to specialization relationship between SOA governance and cloud computing governance, definition of cloud computing governance may be derived from definition of SOA governance. Because SOA governance is a set of components and relationships between these components (Hojaji \& Shirazi, 2012), cloud computing governance is a set of policies, guiding principles, processes, roles and responsibilities extended for cloud computing environment which focuses on effective use of cloud services while minimizing costs and risks, so that cloud services produce the expected business value in accordance with business 
needs (Saidah \& Abdelbaki, 2014). It implies that cloud computing governance must not stand in isolation but it must be part of the overall governance structure in organization.

Proposal of cloud computing governance lifecycle is based on SOA Governance Framework and fully reflects its structure and its methodological components. SOA Governance Framework is methodological framework created by the Open Group to govern and manage service oriented architecture (SOA) (The Open Group, 2009). SOA Governance Framework enables organizations to define and deploy their own SOA Governance Model adapted for specific business environment. SOA Governance Framework consists of SOA Governance Reference Model (SGRM) and SOA Governance Vitality Method (SGVM) which is a process that deploys and improves SGRM (Hojaji \& Shirazi, 2012). SGVM is carried out in a cycle consisting of four phases which are plan, define, implement and monitor (see Figure 2) (The Open Group, 2009). SGVM is a continuous process based on gradual iterations which helps to continuously increase efficiency of SOA Governance.

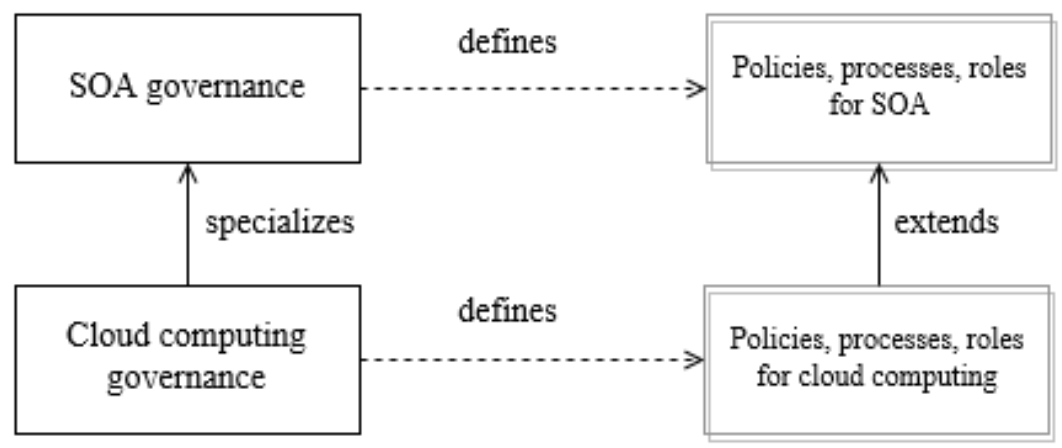

Fig. 2. Specialization and extension relationship between cloud computing governance and other governance systems in organization. Source: authors, based on (Ondruška, 2010).

As SOA governance, cloud computing governance can be implemented in a number of activities carried out in a cycle consisting of planning, definition, implementation and monitoring (as shown in Figure 3) with the aim to establish and improve cloud computing governance model. This cycle called Cloud computing governance lifecycle enables individual adjusting of cloud computing governance model to meet specific business needs as well as a gradual improvement of level of cloud computing governance. As well as SOA Governance Framework, Cloud computing governance lifecycle defines guiding principles, processes, roles and responsibilities and artifacts extended for governing of cloud computing environment. 


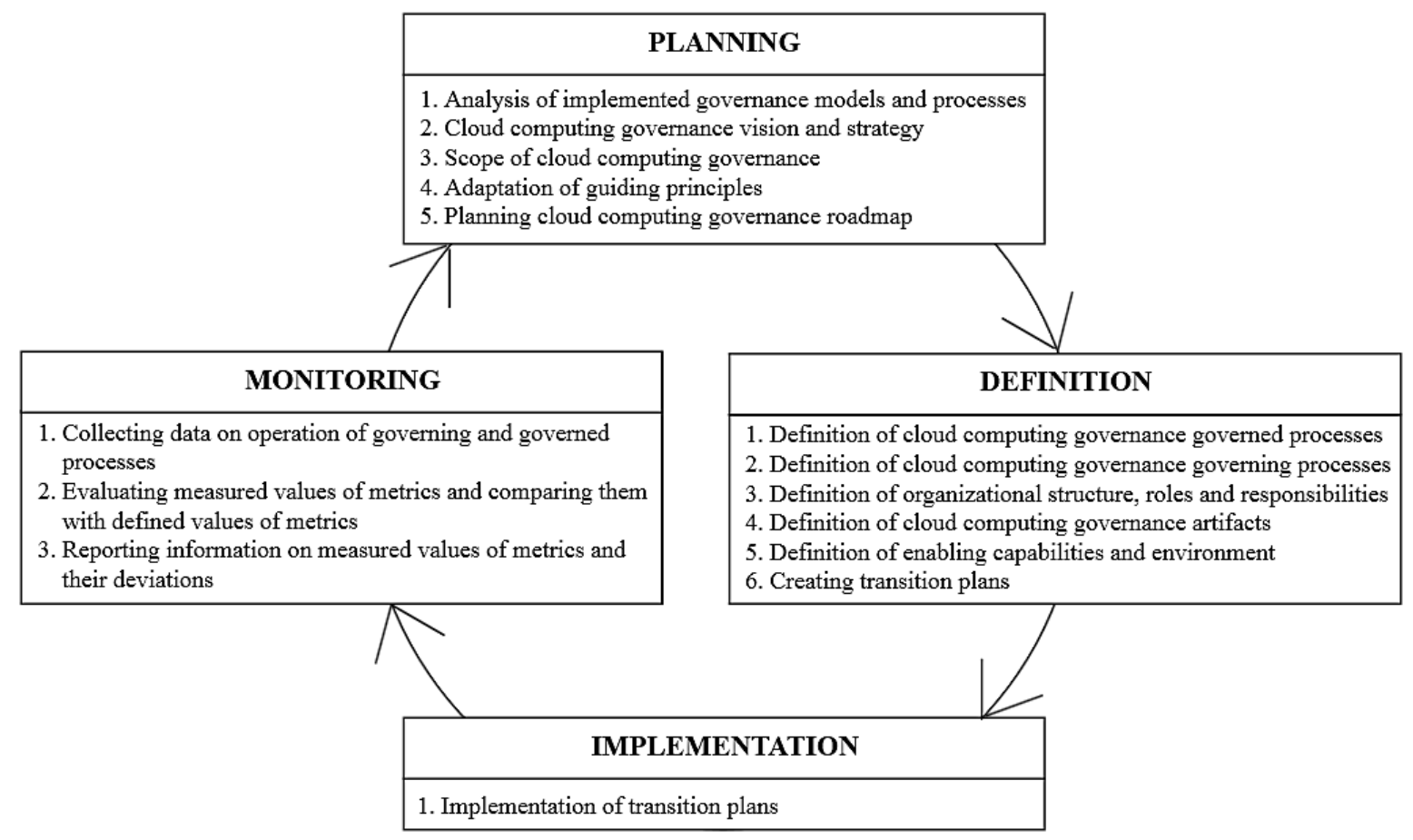

Fig. 3. Cloud computing governance lifecycle. Source: authors.

\subsection{Planning}

Starting point of planning phase is definition of stakeholder needs and business objectives and determine the manner in which these needs and objectives will be fulfilled. Planning phase must respond to changing needs of business processes and compare them with the current state of cloud computing governance.

SGVM defines six activities of plan phase:

1. Understand Current Governance Structures

2. Assess SOA Maturity

3. Develop SOA Governance Vision and Strategy

4. Develop SOA Governance Scope

5. Develop SOA Governance Principles

6. Develop SOA Governance Roadmap

Cloud computing governance lifecycle redefined SGVM plan phase activities and proposes following activities as a part of planning phase:

1. Analysis of implemented governance models and processes

2. Cloud computing governance vision and strategy

3. Scope of cloud computing governance

4. Adaptation of guiding principles

5. Planning cloud computing governance roadmap

\subsubsection{Analysis of implemented governance models and processes}

Analysis of implemented governance models and governance processes existing in the organization means assessing of corporate governance, enterprise governance, enterprise architecture governance, IT governance or SOA governance structure. The goal of this activity is to find starting point for creating or maintaining a cloud computing governance 
model to govern cloud computing environment. Cloud computing governance should be part of IT governance which helps to enforce its implementation.

Assessment of cloud computing governance maturity can help to understand of the maturity level of cloud computing governance within the organization and ensure that cloud computing governance model is defined to a level appropriate for organization to mature cloud computing praxis. Assessment of cloud computing provides feedback to executive management and helps them to define future development of cloud computing governance. Maturity levels of cloud computing governance shows Table 1.

\section{Level 0: Non-existent cloud computing governance}

Cloud computing governance is not implemented. There are no cloud computing governance processes. No recognized need to address cloud computing governance.

\section{Level 1: Initial/ad hoc cloud computing governance}

Missing or inadequate cloud computing governance practices and processes, which are ad hoc, inconsistent and depends on experience of the head of IT department who recognized that cloud computing governance need to be addressed.

\section{Level 2: Repeatable cloud computing governance}

Cloud computing governance policies and processes are defined and implemented by individual managers with senior management involvement and oversight. Business/IT committee is about to formalize. Roles and responsibilities are not explicitly defined. Cloud computing governance policies are not properly communicated.

\section{Level 3: Defined cloud computing governance}

Cloud computing governance policies and governed processes are standardized, implemented, documented and communicated through formal training. There is a clear understanding of roles and responsibilities. Governing processes are not fully implemented and therefore deviations of governed process are not detected. Business/IT committee cooperates in deciding on business and cloud computing goals.

\section{Level 4: Managed and measurable cloud computing governance}

A set of cloud computing governance performance indicators and metrics is set to measure compliance. Cloud computing governance processes are monitored and evaluated based on statistical and quantitative techniques. Governance processes operate within defined limits. Improvement of cloud computing governance in based on quantitative measures. Cloud computing goals align with business goals so cloud computing governance supports creation of business value through realization of benefits from the use of cloud computing services.

\section{Level 5: Optimized cloud computing governance}

Cloud computing governance is part of enterprise governance. Cloud computing governance is optimized, continuously improved and adapted to particular environment. Business/IT committee coordinates and plans business goals and cloud computing goals, business strategy and cloud computing strategy and jointly decide on investments.

Tab. 1. Cloud computing governance maturity levels. Source: authors, based on (Svatá, 2011).

\subsubsection{Cloud computing governance vision and strategy}

The aim of this activity is to create a long-term vision for cloud computing and strategy for realization of this vision. Cloud computing governance vision is based on guiding principles of cloud computing governance and on business strategy. Strategy for realization of vision for cloud computing should contain investment into cloud computing governance evaluation, definition of metrics for measuring value obtained from cloud computing governance and prioritization of activities defined in cloud computing governance strategy. 


\subsubsection{Scope of cloud computing governance}

Definition of scope of cloud computing governance involves:

- Identification of stakeholder needs

- Identification of cloud computing governance processes

- Identification of governance level and selection components of cloud computing governance which govern only relevant and necessary business objects with acceptable cost and in acceptable time

\subsubsection{Adaptation of guiding principles}

The purpose of this activity is adapting cloud computing governance guiding principles for a particular organization in accordance with the principles of enterprise governance and IT governance. Cloud computing governance guiding principles provide a reference for policy makers to support decision making during the design, deployment and operation of cloud computing governance.

SGRM defines SOA governance guiding principles which do not reflect cloud environment and therefore Cloud computing governance lifecycle identified and proposed cloud computing governance guiding principles as follows:

1. Strategic cloud computing initiatives must be in alignment with business strategy and must be supported by executive management

2. Cloud computing governance must be aligned with enterprise governance and IT governance and must be supported by executive management

3. Value delivery from the use of cloud computing services must be ensured and the level of value must be clearly defined, accepted and continuously measured

4. Cloud computing governance should recognize the rights of stakeholders established by law or through mutual contractual agreements which maintain their relationship

5. Cloud computing governance should provide cloud computing services metadata system to manage data related to delivered cloud computing services

6. Cloud computing governance should provide cloud service providers metadata system to manage data related to cloud service providers

7. Effectiveness and performance of implemented cloud computing governance system must be monitored

8. Risk related to utilization of cloud computing services must be continuously optimizing

9. Cloud computing governance practices must be in compliance with legal and regulatory requirements

10. Enabling capabilities and environments must be available to support implementation and operation of cloud computing governance

\subsubsection{Planning cloud computing governance roadmap}

Roadmap of cloud computing governance defines the number of iterations of Cloud computing governance lifecycle. During the implementation of the first cycle, it is performed initial deployment of cloud computing governance. During subsequent iterations, it can be gradually implemented a whole cloud computing governance vision. If during each iteration any change in the use of cloud computing services occurs, this change must be reflected in cloud computing governance roadmap. 


\subsection{Definition}

Definition includes definition of steps required to achieve objectives of planning phase. The outcome from definition phase is a concrete roadmap which define initial deployment of cloud computing governance or planned changes in various areas of cloud computing governance. SGVM defines seven activities of define phase:

1. Define Governed SOA Processes

2. Define Governing SOA Processes

3. Collect SOA Guidelines and Standards

4. Define SOA Governance Organization, Roles, and Responsibilities

5. Define SOA Governance Information Artifacts

6. Define SOA Governance Environment

7. Create Transition Plans

We proposed following activities as a part of definition phase:

1. Definition of cloud computing governance governed processes

2. Definition of cloud computing governance governing processes

3. Definition of organizational structure, roles and responsibilities

4. Definition of cloud computing governance artifacts

5. Definition of enabling capabilities and environment

6. Creating transition plans

\subsubsection{Definition of cloud computing governance governed processes}

Governed SOA Processes include planning, design and operation of aspects of SOA. Their objective is implementation of enforcement of SOA governance. Governed SOA Processes are:

- Service Portfolio Management

- Service Lifecycle Management

- Solution Portfolio Management

- SOA Solution Lifecycle

Governed SOA Processes are intended for managing of SOA services and do not reflect governance of cloud computing services and therefore Cloud computing governance lifecycle proposed cloud computing governance governed processes based on COBIT 5 governance processes (ISACA, 2012). Cloud computing governance governed processes ensure enforcement of cloud computing governance. Proposed cloud computing governance governed processes as follows:

- Ensure cloud computing governance setting and maintenance - process ensures definition of policies, practices, principles, guidelines, processes, organizational structures, roles and responsibilities in order to achieve business objectives and meet stakeholder needs in accordance with enterprise and IT governance

- Ensure benefits from cloud computing services - process ensures that any approved cloud computing service as well as the entire portfolio of approved cloud computing services will produce the expected value to stakeholders while optimizing cost and risk

- Ensure risk management system - process ensures that risk management system for cloud computing services is effective and efficient and it is an integral part of organizational risk management system 
- Ensure system for monitoring and reporting utilization of services in cloud environment - process ensures establishment of internal control system to monitor performance of cloud environment in terms of compliance with business needs, governance policies, contracts, laws and regulations

- Ensure system for managing cloud service providers - process ensures establishment of procedures for selection and evaluation of cloud service providers in terms of the level of risk generated by the quality of their services

The purpose of this activity is to implement governed processes and to identify governed processes which are not in conformance with cloud computing governance in terms of cloud computing governance scope, vision and strategy. This activity defines how should be identified nonconforming governed process modified in order to satisfy the requirements of cloud computing governance.

\subsubsection{Definition of cloud computing governance governing processes}

Governing SOA Processes are constantly executing in organization to govern Governed SOA Processes which are the actual processes being controlled, monitored and measured. Governing SOA Processes are:

- Compliance

- Dispensation

- Communication

Governing SOA Processes are intended for governing Governed SOA Processes and do not reflect above proposed cloud computing governance processes and therefore Governing SOA Processes need to be redefined to cover specifics of cloud computing. Cloud computing governance lifecycle redefined Governing SOA Processes and proposed cloud computing governance governing processes as follows:

- Managing compliance - process ensures that governed process is in compliance with policies of cloud computing governance.

- Managing exception - process manages detected exception and determines whether exception is accepted or rejected with the reason that a cause of exception must be removed

- Managing communication - process ensures that necessary and relevant information relating to cloud computing governance are communicating to relevant stakeholders.

\subsubsection{Definition of organizational structure, roles and responsibilities}

The purpose of this activity is definition of organizational structure of cloud computing governance and related roles and responsibilities. This may be an extension of competences and responsibilities of existing roles in organization or creation new roles and responsibilities associated with specific areas associated with use of cloud computing services.

SOA Governance Roles and Responsibilities defines organizational structures, roles, and responsibilities as a part of SOA Governance Model. Cloud computing governance lifecycle redefined organizational structures and proposed new roles reflecting cloud computing environment and their responsibilities. Proposed cloud computing governance structure, roles and responsibilities shows Table 2 . 


\begin{tabular}{|c|c|c|}
\hline Structure & Role & Responsibility \\
\hline $\begin{array}{l}\text { IT/Business Steering } \\
\text { Committee }\end{array}$ & $\begin{array}{l}\text { Chief Cloud Officer } \\
(\mathrm{CCO})\end{array}$ & $\begin{array}{l}\text { Making strategic decisions regarding cloud computing } \\
\text { governance in conjunction with business executives } \\
\text { Joint coordination and planning of business and cloud } \\
\text { computing goals, business and cloud computing strategy and } \\
\text { investments } \\
\text { Joint decisions on acceptability of cloud computing services }\end{array}$ \\
\hline $\begin{array}{l}\text { Cloud Computing } \\
\text { Governance Board }\end{array}$ & $\begin{array}{l}\text { Cloud Computing } \\
\text { Governance Chief } \\
\text { Cloud Computing } \\
\text { Architect } \\
\text { Cloud Computing } \\
\text { Compliance Chief }\end{array}$ & $\begin{array}{l}\text { Definition of cloud computing goals } \\
\text { Definition of cloud computing strategy } \\
\text { Definition of cloud computing governance vision and } \\
\text { strategy } \\
\text { Definition of scope of cloud computing governance } \\
\text { Responsibility for adoption of cloud computing governance } \\
\text { and adaptation of governance processes, roles and } \\
\text { responsibilities } \\
\text { Responsibility for definition of cloud computing governance } \\
\text { policies, technology and metrics of governance processes } \\
\text { Definition of cloud computing governance roadmap and } \\
\text { transition plans }\end{array}$ \\
\hline $\begin{array}{l}\text { Cloud Computing } \\
\text { Governance } \\
\text { Development Team }\end{array}$ & $\begin{array}{l}\text { Cloud Computing } \\
\text { Governance Analyst } \\
\text { Cloud Computing } \\
\text { Governance Project } \\
\text { Manager } \\
\text { Cloud Computing } \\
\text { Governance } \\
\text { Developer }\end{array}$ & $\begin{array}{l}\text { Responsibility for proposal to change of cloud computing } \\
\text { governance model } \\
\text { Creation of cloud computing governance roadmap } \\
\text { Implementation of transition plan }\end{array}$ \\
\hline $\begin{array}{l}\text { Cloud Computing } \\
\text { Governance } \\
\text { Operation }\end{array}$ & $\begin{array}{l}\text { Cloud Computing } \\
\text { Governance } \\
\text { Operation } \\
\text { Administrator }\end{array}$ & $\begin{array}{l}\text { Administration of cloud computing governance operation } \\
\text { Collection and evaluation of monitoring outcomes of cloud } \\
\text { computing governance processes and escalation detected } \\
\text { deviations }\end{array}$ \\
\hline
\end{tabular}

Tab.2. Cloud computing governance structure, roles and responsibilities.

Source: authors, based on (The Open Group, 2009).

\subsubsection{Definition of cloud computing governance artifacts}

The purpose of this activity is to identify artifacts of cloud computing governance governing and governance processes (e.g. documents) which needs to be adapted, newly create, replace with new artifacts or cancelled. It is important to focus not only the existence or absence of artifacts, but also on their content and correctness.

SOA Governance Information Artifacts are entities used in both Governing SOA Processes and Governed SOA Processes. Cloud computing governance lifecycle redefined these artifacts to be suitable for above proposed cloud computing governance governed processes and cloud computing governance governing processes. Proposed cloud computing governance artifacts shows Table 3 .

\begin{tabular}{|l|l|}
\hline $\begin{array}{l}\text { Cloud computing governance } \\
\text { artifacts }\end{array}$ & Types of cloud computing governance artifacts \\
\hline $\begin{array}{l}\text { Strategical cloud computing governance } \\
\text { artifacts }\end{array}$ & $\begin{array}{l}\text { Statement about acceptance of cloud computing organizations } \\
\text { Cloud computing goals } \\
\text { Cloud computing strategy }\end{array}$ \\
\hline
\end{tabular}




\begin{tabular}{|l|l|}
\hline & Cloud computing governance vision and strategy \\
& Cloud computing governance scope \\
& Cloud computing governance guidelines \\
& Communication plan \\
\hline Cloud computing governance artifacts & Cloud computing governance guiding principles \\
& Cloud computing governance policy \\
& Cloud computing governance processes \\
& List of metrics of cloud computing governance processes and their \\
values & Organizational structure of cloud computing governance \\
& Roles and responsibilities \\
Cloud computing governance technology
\end{tabular}

Tab.3. Proposed cloud computing governance artifacts. Source: authors, based on (The Open Group, 2009).

\subsubsection{Definition of enabling capabilities and environment}

The purpose of this activity is to define technology and tools required for implementation and operation of cloud computing governance. It must be analyzed whether existing enterprise technology and tools can be used for implementation and operation of cloud computing governance including functionality, performance and necessary resources. Further should be performed market analysis which analyzed available technology including their cost effectiveness. Results of analysis serves as a basis for requirements for future state of technology and tools including acquisition of new technology. Technology and tools should be capable to automate cloud computing governance processes and to support cloud computing governance vision, strategy and scope.

\subsubsection{Creating transition plans}

The purpose of this activity is to create transition plans, which define tasks and activities that need to take place to efficiently reach the target state and close gaps between current conditions and a desired future or target state. Transition plan identifies transition team, its organization and its responsibilities, tools, and methods that are needed to perform an efficient and effective transition. Special attention is given to contingency planning and risk mitigation. Due to cloud computing governance is a specialization of IT governance and SOA governance, transition plans of cloud computing governance must be a part of IT and SOA governance transition plans or be fully aligned with them.

\subsection{Implementation}

In this phase transition plans developed in definition phase are implemented. Transition plans define steps and activities which need to be done in accordance with cloud computing governance strategy. 


\subsection{Monitoring}

Monitoring of cloud computing governance covers following activities:

- Collecting data on operation of cloud computing governance governing and governed processes

- Evaluating measured values of metrics and comparing them with defined values

- Reporting information on measured values of metrics and their deviations

Monitoring collects information on performance of cloud computing governance governing and governed processes. It enables to assess cloud computing governance processes whether goals and objectives of cloud computing governance are being met. Evaluation of measured values of metrics enables to specify the level of goals and objectives are met and uses information for improvement. An important aspect of monitoring is ability to evaluate measured data and compare them with set of defined values of metrics which provide a basis for decision on cloud computing governance performance. To properly assess the level of cloud computing governance performance, it is necessary to monitor events caused by a change in business strategy, cloud computing strategy, organizational structure or changes in legislation.

Monitoring must be continuous to provide current and correct information. Evaluation of measured data is performed depending on their importance also either continuously or at regular time intervals according to business needs.

\section{Verification of Cloud computing governance lifecycle}

Verification of the practical applicability of proposed Cloud computing governance lifecycle is realizing on a case study conducting in large IT organization which provides IT services to a large retail organization operating within EU. The case study is carried out in accordance with the methodology for the design and implementation of case studies for scientific purposes as defined in publication Case Study Research: Design and Methods (Yin, 2009). IT organization has decided to utilize a cloud computing service. Given that IT organization has not used any cloud computing service so far, project of planning, selection, implementation, operation and monitoring is considered as Proof-of-Concept project. In addition to this project, the aim of case study is to adapt the existing IT governance model using proposed Cloud computing governance lifecycle. Since the implementation of cloud computing governance is a very complex process, expected project completion and adaptation of existing IT governance model is planned for the end of 2016.

\section{Discussion and conclusion}

Cloud computing governance has a great significance in helping to meet business requirements through using of cloud services. As cloud computing continues to increase its importance it is essential that organizations understand how to meet business objectives through utilizing of cloud computing services and achieve a higher level of business IT alignment, how to obtain benefits from cloud computing services and how to optimize cloud investments and related risks. Although there is no accepted framework for cloud computing governance, organizations can to adapt principles and processes from existing frameworks such as COBIT 5 or SOA governance to govern cloud computing services. The question remains how to adapt these frameworks and which principles and processes are relevant for cloud computing. However, a problem arises in their implementation as well. Proper 
implementation of cloud computing governance has a great impact on business value creation and on level of gained benefits from cloud services utilization. There are some difficulties that organizations face while deploying cloud computing governance such as integrating cloud computing governance into existing governance structures in organization, planning cloud computing governance roadmap, designing effective cloud computing governance structures or lack of consistent governance processes. Guidance on implementation of cloud computing governance helps to overcome these difficulties and facilitate deployment.

This paper proposed Cloud computing governance lifecycle as a partial result of research in the field of governing public cloud computing services from cloud consumer view. Cloud computing governance lifecycle is based on SOA Governance Vitality Method and on literature reviews on SOA and IT governance frameworks. Starting point of cycle is by first assessing both governance structure in organization and maturity level of cloud computing governance if implemented, and then putting effort to define where the organization wants to be in the meaning of cloud computing governance vision, strategy and its scope. Part of planning cloud computing governance must be planning roadmap to implement strategy into praxis. In definition phase, an overview of cloud computing governance governed processes, governing processes, organizational structure with should be established along with cloud computing governance, roles and their responsibilities, needed technology and artifacts are provided. Definition phase is ended by creation of transition plans which must be implemented in a next step. Last part of cycle is monitoring deviations from claimed parameters which has a potential to start cycle from the beginning.

The future efforts will focus on a more detail definition of Cloud computing governance lifecycle and on developing comprehensive Cloud computing governance frameworks.

\section{References}

Bailey, E. \& Becker, J. (2014). A Comparison of IT Governance and Control Frameworks in Cloud Computing. Savannah. In Proceedings of the 20th Americas Conference on Information Systems, AMCIS 2014, (pp. 1-16). New York: Association for Information Systems.

Bayramusta, M., \& Nasir, V. (2016). A fad or future of IT?: A comprehensive literature review on the cloud computing research. International Journal of Information Management, 36(4), 635-644. doi: 10.1016/.ijinfomgt.2016.04.006

Biske, T. (2008). SOA Governance: The key to successful SOA adoption in your organization. Birmingham: Packt Publishing.

Brandis, K., Dzombeta, S., \& Haufe, K. (2013). Towards a framework for governance architecture management incloud environments: A semantic perspective. Future Generation Computer Systems, 32, 274-281. doi: 10.1016/j.future.2013.09.022

Dehghani, M., \& Emadi, S. (2015). Developing a Framework for Evaluating Service Oriented Architecture Governance with Approach COBIT. Cumhuriyet University Faculty of Science, Science Journal, 36(4), 797-806.

Erl, T. (2007). SOA Principles of Service Design. New Jersey: Prentice Hall.

Feuerlicht, G., Schneider, S. \& Tranter, L. (2012). Towards Enterprise Architecture for Cloud Computing Environments. In Proceedings of the 11th Workshop of on e-Business, (pp. 412-422). Orlando: University of North Carolina at Charlote.

Fortis, T.-F. \& Munteanu, V. (2014). From Cloud Management to Cloud Governance. In Mahmood, Z. (Ed.), Continued Rise of the Cloud, (pp. 265-287). New York: Springer. doi: 10.1007/978-1-4471$\underline{6452-411}$

Gai, K., \& Li, S. (2012). Towards Cloud Computing: A Literature Review on Cloud Computing and Its Development Trends. In Proceedings of the Fourth International Conference on Multimedia 
Information Networking and Security 2012, (pp. 142-146). Nanjing: IEEE. doi: $\underline{10.1109 / M I N E S .2012 .240}$

Hojaji, F., \& Shirazi, M. (2010). AUT SOA governance: A new SOA governance framework based on COBIT. In Proceedings of the 3rd IEEE International Conference on Computer Science and Information Technology, (pp. 403-408). New York: IEEE. doi: 10.1109/ICCSIT.2010.5564486

Hui-min, Z., Hai-rong, H., Yang-xia, X. \& Lu-lu, F. (2013). The Research and Design of Cloud Computing Framework Model Based on SOA. In Proceedings of the International Workshop on Cloud Computing and Information Security, (pp. 81-84). Amsterdam: Atlantis Press.

IBM. (2009). SOA Governance and Service Lifecycle Management. Retrieved from http://www$01 . \mathrm{ibm} . \mathrm{com} / \mathrm{software} / \mathrm{solutions} / \mathrm{soa} / \mathrm{gov} /$

ISACA. (2014). Controls \& Assurance in the Cloud: Using COBIT 5. New York: ISACA.

Jäntti, M. \& Hotti, V. (2015). Defining the relationships between IT service management and IT service governance. Information Technology and Management, 17(2), 141-150. doi: 10.1007/s10799-015-0239-z

Joukhadar, G. \& Rabhi, F. (2013). Effective Governance During SOA Lifecycle - Theory and Practice. In Service Research and Innovation Third Australian Symposium, ASSRI 2013, (pp. 15-28). Sydney: Springer. doi: 10.1007/978-3-319-07950-9 2

Joukhadar, G. \& Rabhi, F. (2015). SOA in practice - a study of governance aspects. Information Systems Frontiers, 18(3), 499-510. doi: 10.1007/s10796-015-9607-9

Königsberger, J., Silcher, S. \& Mitschang, B. (2014). SOA-GovMM: A meta model for a comprehensive SOA governance repository. In Proceedings of the 15th International Conference on Information Reuse and Integration, (pp. 187-194). Redwood City: IEEE. doi: $\underline{10.1109 / I R I .2014 .7051889}$

Laird, R. (2011). SOA Sets the Stage for Cloud: SOA Governance Makes It Work. Service Technology Magazine, (56). Retrieved from http://www.servicetechmag.com/system/application/views/156/1111-2.pdf

Linthicum, D. (2009). Cloud Computing and SOA Convergence in Your Enterprise. A Step-by-Step Guide. New Jersey: Pearson Education.

Mircea, M. (2010). SOA, BPM and Cloud Computing: Connected for Innovation in Higher Education. In Proceedings of the International Conference on Education and Management Technology (pp. 456-460). Cairo: IEEE. doi: 10.1109/ICEMT.2010.5657616

Munteanu, V., Fortiş, T.-F. \& Copie, A. (2013). Supporting Cloud Governance through Technologies and Standards. In Zavoral, F., Jung, J. J., Badica, C. (Eds.) Intelligent Distributed Computing VII, (pp. 271-280). Berlin: Springer. doi: 10.1007/978-3-319-01571-2 32

Niemann, M., Eckert, J., Repp, N. \& Steinmetz, R. (2008). Towards a Generic Governance Model for Service-oriented Architectures. In Proceedings of the 14th Americas Conference on Information Systems (paper 361). New York: Association for Information Systems.

Ondruška, M. (2010). Model propojení IT Governance a životního cyklu aplikace. Systémová integrace, 17(3), 108-119.

Oracle. (2013). Oracle SOA Governance. Retrieved from http://www.oracle.com/us/products/middleware/soa/governance/overview/index.html

Pour, J. (2012). Výsledky průzkumu řízení podnikové informatiky. Systémová integrace. 19(1), 49-57.

Ritchey, R. (2009). Governance Considerations Governance Considerations. Retrieved from http://scap.nist.gov/events/2009/itsac/presentations/day3/Day3 Cloud Ritchey.pdf

Saidah, A. \& Abdelbaki, N. (2014). A New Cloud Computing Governance Framework. In Proceedings of the 4th International Conference on Cloud Computing and Services Science, (pp. 671-678). Setúbal: Science and Technology Publications.

Surya, G. \& Surendro, K. (2014). E-Readiness Framework For Cloud Computing Adoption in Higher Education. In Proceedings of the International Conference of Advanced Informatics: Concept, Theory and Application, (pp. 278-282). Bandung: IEEE. doi: 10.1109/ICAICTA.2014.7005954 
Susanti, F., \& Sembiring, J. (2011). The Mapping of Interconnected SOA Governance and ITIL v3.0. In Proceedings of the International Conference on Electrical Engineering and Informatics, (pp. 1-5). New York: IEEE. doi: 10.1109/ICEEI.2011.6021574

Svatá, V. (2011). Audit informačního systému. Praha: Professional Publishing.

The Open Group. (2009). SOA Governance Framework. Retrieved from:

https://www.opengroup.org/soa/source-book/gov/gov.htm

The Open Group. (2013). SOA and Enterprise Architecture. Retrieved from: http://www.opengroup.org/soa/source-book/soa/soa ea.htm

Yin, R. K. (2009). Case Study Research: Design and Methods. New York: SAGE Publications.

Zhao, J.-F. \& Zhou, J.-T. (2014). Strategies and Methods for Cloud Migration. International Journal of Automation and Computing, 11(2), 143-152. doi: $\underline{10.1007 / \mathrm{s} 11633-014-0776-7}$ 